$\left.1960^{\prime \prime}\right)$, and he derived statistical measures devised to quantify the relationship between changes in export and money incomes.

The concept of the African personality was presumed to have a social significance by Cleo Kumalo ("Toward a Sociological Approach to the Concept of the African Personality"), and he went on to raise the basic question of whether and how that reference can be discovered through the logico-experimental method of science. In his topical talk, Donald S. Rothchild ("Progress and the One-party State") concluded that the evidence for a correlation between political processes and economic progress is neither complete nor convincing. R. C. Bridges ("Are Explorers Redundant in East African History?") asserted that impressions given in Europe by explorers' exploits created a "frame of reference" within which missionaries and administrators worked, and in this way explorers' work is, indeed, a factor in the history of East Africa. Another topical talk was that given by A. K. Mayanja ("The Rule of Law in Emergent African States"), who recommended that both the formal and metalogical aspects of the rule of law need to be insured against legislative erosion.

Jonathan Silvey ("Formal and Informal Learning through the Medium of a Second Language") considered
Bernstein's concept of public and formal (or individualized) language in relation to the language modes characteristic of rural and educational life in East Africa. These meetings were ended by J. Kariuki ("Poetic Works") reciting a number of his own poetic works.

The proceedings of the entire symposium are to be published. This is just one of the many decisions made at the annual general meeting and the meeting of the Executivo Council. Others are the decision to hold the next symposium meeting in Nairobi next May; the appointment of several standing committees (Research and Studentships, Conferences and Liaison, Editorial and Symposium, Education, and Membership); collaboration with the Ghana Academy of Sciences in bringing to fruition the Encyclopaedia Africana project; decision on the principle of admitting societies operating within East Africa to institutional membership; and plans for bringing about the formal recognition of the Academy as their national academy by the East African Governments. Dr. N. C. Otieno, lecturer in botany, Royal College, Nairobi, was elected president of the Academy, Dr. J. Njoroge (plant pathologist, Scott Agricultural Laboratories, Kabete), secretary, and Mr. M. Alala (lecturer in mathematics, Royal College, Nairobi), treasurer.

Thomas R. Odhtambo

\title{
THE DELHI PILLAR
}

$\mathrm{T}$ HE mystery which has enveloped this quite remark able piece of metal should be once and for all removed as a result of three papers published in the February issue of the Journal of the National Metallurgical Laboratory of India $(5,24 ; 1963)$. All that has been previously written is summarized and the theories propounded to explain its resistance to corrosion are collected. Despite efforts by M. K. Ghosh and by Lahiri, Banerjee and Nijhawan to support the view that there was something about the manufacture of the metal which endowed this remarkable forging with special resistance, there can be little doubt that Bardgett and Stannors's conclusions deserve acceptance.

Made by hammer-welding small balls of native iron of a fairly wide range of carbon contents, its resistance to corrosion during the 1,600 years or so of its existence is ascribed to the combined influence of a number of normal, favourable factors. Among these are included the climate and freedom from pollution of the atmosphere which exceeds Vernon's critical humidity of about 80 per cent for less than 5 per cent of the year. Secondly, to a progressively decreasing rate of attack due to the building up of a protective layer of oxide and scale during the early years of oxposure.

That in the past on ceremonial occasions the pillar was anointed appears to be probable, while even to-day it is repeatedly handled. This is supported by the X-ray analysis of a minute sample of the surface coating about $5 \mathrm{ft}$. above the base which contained no iron and only quartz and chalk providing another source of protection. The authors conclude, and it is impossible to disagree with them, that "It is evident that a number of favourable factors have been acting simultaneously and the sum total of the information leads to the view that, although one may justly admire the skill and technology of the early Indian ironworkers in producing so large monument, there is no reason for surprise at the longevity of the pillar. The composition and structure of the iron or its method of manufacture can only have contributed in a minor degree to its preservation and are in no way essential for this. The present authors, indeed, are as confident as one can be in such matters that, given the same circumstances and environment, a pillar forged from modern tonnage steel would, after 1,600 years, have been practically as preserved". Coming from men of such experience and in view of all the evidence here set out, it is impossible to disagree with this view.

The other two papers also discuss the technological aspects of ancient iron-making in India and confirm the account given in Percy's book on iron and steel of a hundred years ago. In particular, they refer in some detail to the iron beams at the Sun Temple of Konarak which show similar resistance to corrosion to the Delhi pillar despite the fact that they are situated on the sea coast. Lahiri, Banerjee and Nijhawan's insistence on the protective influence of envelopes of slag around the metal may here have exercised a decisive influence.

F. C. THOMPson

\section{RECOGNITION OF SEDIMENTARY ENVIRONMENTS}

GOR $\mathrm{R}$ more than a contury geologists have striven to discover criteria by which the environmont of deposition could be inferred from the characteristics of arenaceous rocks. Concentration on one or another aspect has changed over tho years, providing a mass of data which have underlined the breadth of the problem without providing a simple solution.

Investigations of the particle size distribution of modorn sediments have shown that many environments can share similar distributions, while work on the hydraulic aspects of particle transport and deposition has failed to explain the complex nature of many natural sediments. For some years there has consequently been a tendency to rely less on granulometric analyses and more on forms of bedding, such as ripple marks, laminations, and other small sedimentary structuros. But here also there are hints that few, if any, of the supposedly diagnostic features aro unique to any one environment, and the feeling is gaining ground that the environment in which a given sample was deposited can only be deducod reliably by considering the complete suito of associated sediments. 